Cadernos de História, Belo Horizonte, v. 22, n. 37, Novembro de 2021

DOI: https://doi.org/10.5752/P.2237-8871.2021v22n37p144-164

\section{MEMóRIAS DE “DOIS CAPOEIRAS AOS PÉS DO BERIMBAU": OCUPANDO ESPAÇOS E SUPERANDO OS DESAFIOS EM VITÓRIA DA ConQuista-BA (1980-2017)}

Jonatan dos Santos Silva

Universidade Estadual do Sudoeste da Bahia jonatandon@gmail.com

Marlon Messias Santana Cruz Universidade do Estado da Bahia mmscruz@uneb.br

Isabele Pires Santos Soler

Universidade Estadual do Sudoeste da Bahia beuca.isa@gmail.com

Felipe Eduardo Ferreira Marta Universidade Estadual do Sudoeste da Bahia fefmarta@gmail.com

\title{
RESUMO
}

A história oral é discutida neste estudo como parte da perspectiva dialógica com as fontes orais, eixo para a constituição de questões vinculadas à memória. A existência de tensões ocasionadas pelos conflitos ao longo do processo de disseminação da capoeira em Vitória da Conquista-BA mostrouse, como reflexo, nas lutas enfrentadas atualmente pelos Mestres Acordeon e Pantera, apontados na cidade como os principais disseminadores da capoeira nas décadas de 1980 a 2017. A memória desses conflitos possibilitou investigar o processo de disseminação da capoeira na cidade até os anos 2000. Para tanto, utilizamos como referencial teórico-metodológico os escritos de Portelli (1997) e Meihy (2010). Os resultados mostraram dificuldades relacionadas à busca de empregabilidade e sustentabilidade; desmoralização; resistência ao preconceito racial; enfrentamentos políticos; disputas de memórias; ocupação de espaço e autonomia.

Palavras-chave: Memória; Capoeira; Tensões; Conflitos; Vitória da Conquista-BA.

Recebido em 10 de novembro de 2020.

Aprovado em 23 de fevereiro de 2021. 
Cadernos de História, Belo Horizonte, v. 22, n. 37, Novembro de 2021

DOI: https://doi.org/10.5752/P.2237-8871.2021v22n37p144-164

MEMORIES OF “DOIS CAPOEIRAS AOS PÉS DO BERIMBAU”: OCCUPYING SPACES AND OVERCOMING THE CHALLENGES IN VITÓRIA DA CONQUisTA-BA (1980-2017)
Jonatan dos Santos Silva

Universidade Estadual do Sudoeste da Bahia jonatandon@gmail.com

Marlon Messias Santana Cruz

Universidade do Estado da Bahia mmscruz@uneb.br

Isabele Pires Santos Soler

Universidade Estadual do Sudoeste da Bahia beuca.isa@gmail.com

Felipe Eduardo Ferreira Marta Universidade Estadual do Sudoeste da Bahia fefmarta@gmail.com

\begin{abstract}
Oral history is discussed in this study as part of the dialogical perspective with oral sources, an axis for the constitution of issues linked to memory. The existence of tensions caused by conflicts throughout the disseminated process of capoeira in Vitória da Conquista-BA was reflected in struggles currently faced by the Mestres Acordeon and Pantera, considered in the city as the highest exponent in capoeira in the 80 s and $2017 \mathrm{~s}$. The memory of these conflicts made it possible to investigate the process of dissemination of capoeira in the city until the 2000s. For that reason, we used as a theoreticalmethodological framework the writings of Portelli (1997) and Meihy (2010). The results showed difficulties related to the look for employability and sustainability; demoralization; resistance toward racial prejudice; political confrontations; issues of memory; occupation of space and autonomy.
\end{abstract}

Keywords: Memory; Capoeira; Tensions; Conflicts; Vitória da Conquista-BA. 


\section{INTRODUÇÃO: ASPECTOS TEÓRICO-METODOLÓGICOS}

Quando iniciamos este estudo sobre os conflitos e tensões envolvendo a presença da capoeira no processo de urbanização na cidade de Vitória da Conquista, não tínhamos dimensão de que as fontes orais insistiam em trazer eventos ligados à história de seus grupos em suas vivências na cidade. $O$ diálogo feito com os Mestres abriu possibilidades de lançar perguntas que emergiram da necessidade daquele contexto.

Assim, esta pesquisa teve como objetivo investigar as tensões e disputas geradas durante o processo de disseminação da capoeira em Vitória da Conquista-BA, buscando analisar os relatos dos Mestres de Capoeira da cidade, que foram apontados como os principais disseminadores desta prática corporal nesse local, delimitando uma baliza cronológica, traçada desde a década de 1980 até os anos 2000, período segmentado pela memória dos próprios Mestres entrevistados. Entende-se que a lembrança dos conflitos estaria guardada (silenciada) na memória desses indivíduos que contribuíram nesse processo.

Para isso, utilizou-se a História Oral como método que contribuiu para a compreensão, recriação e aprendizado crítico do presente, o que possibilita conhecer as dificuldades enfrentadas e a História Oral de vida, conforme o referencial teórico-metodológico pautado nas produções de Maurice Halbwachs (2006), Alessandro Portelli (1997) e José Carlos Meihy (2010). Os dados da pesquisa foram revelados a partir de entrevistas e coleta de relatos orais, seguindo o método qualitativo, tendo os Mestres de Capoeira da cidade como protagonistas na realização desta pesquisa, são eles: Antonio Santos Ferreira Filho (o Mestre Acordeon) e Gomar Santos Novais (o Mestre Pantera).

Nesse sentido, foi eleito como lócus deste trabalho a cidade de Vitória da Conquista, localizada no interior da Bahia, "palco de uma dinâmica urbana repleta de contradições e conflitos" (FERRAZ, 2001, p. 21). Ferraz (2001) afirma que o fato de se situar em um "entroncamento rodoviário", devido à presença da BR 116, "que faz a ligação Norte-Sul do País", influenciou o desenvolvimento econômico da cidade, que assumiu um papel fundamental enquanto ponto de articulação entre a região Nordeste e o Centro-Sul do País, além de ser a terceira maior cidade da Bahia, com desenvolvimento intensificado "a partir da década de 1940 (...) passando a expandir a sua malha urbana num processo crescente" (FERRAZ, 2001, p. 22).

\section{Memória, corpo/Capoeira e História Oral}

A memória é um fenômeno multimodal que possibilitou tratar a capoeira como fio condutor desta pesquisa. Utilizamos a História Oral para compreender as tensões e disputas durante o processo de disseminação da capoeira na cidade com base nos relatos orais dos Mestres que iniciaram suas trajetórias de disseminação dessa arte, a partir da década de 1980, seguindo os apontamentos de Portelli (1997). Esse autor se refere aos relatos orais como documentos do presente sob a responsabilidade do entrevistado e do entrevistador, um presente compartilhado:

A essencialidade do indivíduo é salientada pelo fato da História Oral dizer respeito a versões do passado, ou seja, à memória. Ainda que esta seja sempre moldada de diversas formas pelo meio social, em última análise, o ato e a arte de lembrar jamais deixam de ser profundamen- 
te pessoais. A memória pode existir em elaborações socialmente estruturadas, mas apenas os seres humanos são capazes de guardar lembranças. Se considerarmos a memória um processo, e não um depósito de dados, poderemos constatar que, à semelhança da linguagem, a memória é social, tornando-se concreta apenas quando mentalizada ou verbalizada pelas pessoas. A memória é um processo individual, que ocorre em um meio social dinâmico, valendo-se de instrumentos socialmente criados e compartilhados. Em vista disso, as recordações podem ser semelhantes, contraditórias ou sobrepostas. Porém, em hipótese alguma, as lembranças de duas pessoas são - assim como as impressões digitais, ou, bem da verdade, como as vozes - exatamente iguais. (PORTELLI, 1997, p. 16).

Para Caldas (1999), a História Oral é reconhecida por vários pesquisadores como metodologia que contribui para compreensão, recriação e aprendizado crítico do presente, que vai possibilitar que os diálogos sejam reconstruídos. Segundo Aróstegui (2006), os pesquisadores dessa área afirmam que a temática trazida por ela adentra a realidade social, alcançando os grupos marginais ou em vias de desaparecimento, discriminados, submetidos, analfabetos etc., o que permite visualizar a história por um ângulo pouco visto pelos historiadores. Meihy (2002) nos alerta sobre a confusão existente no uso dos termos: memória grupal, coletiva e social e até da própria história. Para ele, a memória é um suporte para as narrativas da história oral, mas não a história em si.

A capoeira, como objeto de estudo desta pesquisa, ofereceu oportunidades de criar diálogos entre os estudos de Meihy (2010) e outras fontes, bem como de manter o diálogo com a documentação encontrada a partir dos relatos dos entrevistados. Dessa forma, as fontes documentais vão relativizar o peso dado aos relatos (ibid.). As entrevistas, para Meihy (2010), devem ser a base de efetivação dos resultados para serem garantidas como método. Por isso, ele define História Oral como sendo um recurso usado para elaborar documentos, arquivamentos e estudos relacionados a experiências sociais, pessoais e grupais. É uma prática de apreensão de narrativas feitas por meios eletrônicos, destinada a recolher testemunhos e a promover análises de processos sociais do presente. Ela é precedida por procedimentos definidos em um projeto (MEIHY, 2010, p. 14).

A História Oral, neste trabalho, lança o olhar sobre os Mestres como sujeitos ativos no processo de construção da memória em torno deles. Consideram-se os aspectos ligados às diferentes classes, papéis exercidos e espaços sociais como uma metodologia interessante por levar em consideração os problemas levantados, para que a história ganhe uma nova dimensão. Embora essa área em questão, vista enquanto método, ainda mantenha tabus em relação a sua relevância e fidedignidade entre outros pesquisadores, estamos levando em consideração que, assim como os documentos construídos a partir de novas fontes e de relatos orais são passíveis de questionamentos, podemos também indagar sobre a fidedignidade de documentos oficiais credibilizados pelas fontes oficiais, por serem passíveis de dúvidas.

As narrativas dos Mestres foram coletadas a partir dos apontamentos do referencial específico dos estudos da memória, presentes no trabalho de Portelli (1997). Estabelecemos as condições visando priorizar o que os Mestres desejavam falar, ao invés de valorizarmos o que propomos pesquisar previamente. Esse procedimento favoreceu a construção das memórias em um contexto partilhado por todos os envolvidos nesse processo de disseminação.

De acordo com Tavares (2012), Capoeira é uma construção realizada a partir das matrizes civilizatórias africanas, que tem a Roda como elemento que se transforma em 
espaço da vida cotidiana, materializada pela organização condensada do mundo específico da comunidade, das energias cósmicas canalizadas pela rítmica do berimbau e pelos corpos em movimento, gerando e fazendo girar o axé - força vital. Essa força é o sustentáculo das relações sociais existentes na Roda de Capoeira que, no seu giro, transcende o lugar físico e busca energias na ancestralidade para recarregar o corpo e preparar os participantes para a vivência na sociedade.

Para Oliveira (2006), essa retroalimentação energética é característica filosófica da cosmovisão afro-brasileira: o tempo dos ancestrais é o tempo passado e o tempo de agora. A Roda nos remete a elementos fundamentados nas bases africanas, ao permitir que o jogo aconteça, assim como a brincadeira, o canto, a dança, o toque e a luta, sendo construída no processo civilizatório dos povos negros em território denominado Brasil.

A definição de capoeira como luta, assim referenciada aqui, corrobora os entendimentos dos Mestres que deram vozes a essa dissertação e também parte da definição sobre essa prática enquanto "jogo atlético, dança e luta, brincadeira e combate, mandingueira e objetiva, malandra e vadia (...) sendo a resistência de um povo integrado à massa, é cultura, é raça, enfim é o fenômeno inacabado" (SILVA, 2003, p. 35). Historicamente, o objeto de nosso estudo é marcado pelas tensões geradas a partir de conflitos e disputas existentes na sociedade. Isso porque ela sofreu constantes alterações, pois, conforme afirma Reis (1994), consideramos o corpo como uma construção social, além de contemplar a busca incessante pela reivindicação e ampliação da participação política na sociedade brasileira.

Esse jogo é chamado por Sodré (1983) de jogo da sedução, cujos movimentos incessantes cadenciados e sutis, com sua mandinga ${ }^{1}$ - vão estruturando a estratégia de envolver o oponente sem que ele perceba, seduzindo-o para o golpe final. Um jogo de destreza e malícia em que se finge lutar, e finge-se tão bem que o conceito de verdade da luta se dissolve aos olhos do espectador e do adversário desavisado (SODRÉ, 1983).

Essa dualidade característica da capoeira luta/dança fundamentou a resistência dos povos negros em terras brasileiras, simbolizando uma estratégia cultural, um jogo de resistência estruturado na roda, que se deu a partir do processo de esportivização das práticas corporais empregadas na ideia de "civilização", no intuito de manter o controle e as regras da vida social durante as vivências práticas (ELIAS; DUNNING, 1995). Isso contrapõe o discurso de que a esportivização não descaracteriza a Capoeira em sua essência e tradicionalidade, como afirmam os estudos de Alves e Montagner (2008) sobre os pontos positivos e negativos desse processo.

Com vista no fenômeno descrito por Cid (2018), a respeito da dualidade entre os termos "esportivização" e "culturalização" da capoeira, existe uma tensão contínua entre ambos, devido a essa arte ter sofrido o processo de criminalização à sua aceitação social, ao passo que seu processo de descriminalização se vinculou à ideia de uma prática folclórica, demarcada tipicamente como prática "genuinamente brasileira".

Analisando e compreendendo tal arte como organismo civilizatório de povos negros a partir da diáspora forçada no Brasil, percebe-se toda uma construção fundamentada em princípios de legado africano, como a circularidade - elemento estruturante das sociedades africanas no Brasil, inter-relacionando a cultura à história com as pessoas e às estruturas de contextos sociais. Nesse processo diaspórico, o que vem para o Brasil são os valores e 1 Pode ser traduzido como "encanto" e "malícia". 
princípios negro-africanos (OLIVEIRA, 2006), pois todos os contextos se organizam em círculos e neles vão se construindo o saber e o fazer, envolvendo a relação do ser humano com o mundo, com a terra, com a ancestralidade e com a espiritualidade (RUFINO, 2013).

\title{
O MESTRES ACORdeOn E AS VIVÊNCIAS CONFLITUOSAS DURANTES A DISSEMINAÇÃO
}

As recordações individuais ${ }^{2}$ nos dão pistas para entendermos os caminhos da disseminação da capoeira, em Vitória da Conquista-BA, no período da década de 80 e 90, e como essas experiências vivenciadas pelos Mestres de Capoeira da cidade foram importantes para manter essas memórias coletivas, como diria Halbwachs (2006). A memória do Mestre Acordeon carrega marcas de superação de momentos difíceis da vida; ao mesmo tempo em que reconhece seu legado de Mestre, reporta também a memória de quando presenciou, pela primeira vez, a capoeira nesse contexto, o que revela uma cidade com características distintas de uma realidade semelhante a uma cidade urbanizada.

Embora a década de 1970 já apresentasse locais característicos de uma cidade urbanizada, é possível perceber que o cotidiano das pessoas mantém características típicas de uma localidade rural. O relato do Mestre Acordeon chama atenção para o vaqueiro que praticava esse esporte. Ainda sobre a infância, ele relata, com muita emoção, memórias que marcaram sua passagem pela escola, destacando situações precárias desde a falta de material escolar até a infraestrutura, conforme pode ser observado a seguir:

\begin{abstract}
[...] $\mathrm{Na}$ escola realmente eu fiquei numa situação assim muito triste porque eu queria ter acesso a uma escola que me desse alguma condição digna de respeito e quando eu ia para escola às vezes era pedido para sentar no chão, não tinha... (momento de choro e emoção) ... Aí mexe... às vezes em algum momento minha Vó falava para meu avô a importância de um estudo, em alguns momentos me incentivava, vinha saber o que eu estava passando e eu apanhava né, às vezes eu era tratado de uma forma dura... Eu não tinha cadernos bons, livros bons, lápis... Às vezes eu tinha que pegar emprestado com os colegas na sala, aí é visto hoje como "bullying", como preconceito, mas eu sofri muita coisa dentro da escola (muito emocionado) que isso acabou levando a desistir (momento de silêncio) (informação verbal).
\end{abstract}

Essa memória nos ajuda a refletir o quanto a educação se mostrava excludente no período vivenciado por ele. Além disso, se relacionar ao preconceito está vinculado à desmoralização que sofria perante os demais colegas da escola que, na maioria das vezes, passava despercebida pelos educadores, aumentando nele, ainda mais, o desejo de não estar naquele lugar e continuar lutando, através dos trabalhos informais, como forma de ajudar nas despesas de sua família. Como ele relata a seguir, não havia oportunidades de empregos acessíveis que pudessem ajudar o trabalhador a ascender socialmente, principalmente por se tratar de um praticante de capoeira.

2 É importante frisar, neste momento, que a discussão sobre recordação apresentada neste estudo trata-se da memória individual dos Mestres entrevistados, entendendo que a memória individual é o ponto de vista da memória coletiva, de acordo com Halbwachs (2006). 
O Mestre Acordeon traz relatos do processo de disseminação dessa prática cultural em Vitória da Conquista, em vários locais diferenciados, a partir da sua vivência com o Mestre Zoião ${ }^{3}$ :

[...] Falar da Capoeira dentro da nossa comunidade de Vitória da Conquista e ainda rodou os bairros, e aí teve o próprio local do Parque de Exposição, ele teve no próprio CSU4 ${ }^{4}$ Ginásio de Esportes, teve no "alto das Pedrinhas", foi para o bairro Aparecida, Guarani... Não tinha tanto salões que nós temos hoje, quadras... Então quando ele montou no Edvaldo Flores, como ficou muito distante para muitas crianças, ele trouxe a proposta para o prefeito Hélio Ribeiro ${ }^{5}{ }^{6}$

Assim, para ele, esse processo de disseminação foi possível devido à aproximação do Mestre Zoião com o prefeito responsável pela gestão da cidade, no início da década de 1980 . O então prefeito, Hélio Ribeiro, reconhecia que a cidade tinha "uma carência nesse desenvolvimento prático e humano da arte da Capoeira". Com isso, o Mestre Zoião "levou o prefeito, e houve uma discussão saudável e com certeza ganhamos instrumentalização, roupas e todo atendimento"».

De acordo com o Mestre Acordeon, após a passagem do Mestre Zoião pela cidade, nos anos de 1960, durante suas viagens por várias cidades no País rumo ao Sudeste, decidiu retornar a Vitória da Conquista-BA, no início dos anos de 1980, fundando uma escola de capoeira, após ter se apresentado por todo o estado da Bahia, permanecendo definitivamente na cidade, desde 1988 até falecer nos anos 2000.

No Livro Arte da Capoeira: História e Filosofia, de autoria do Mestre Zoião, consta que depois de ter retornado a Salvador-BA e ter encontrado incentivo de sua família para dar continuidade aos trabalhos do Mestre Bimba, o Mestre Zoião decidiu passar uma temporada na cidade de Vitória da Conquista para desenvolver um trabalho na área de caprinocultura na região e também de capoeira. Dessa forma, dedicou-se a "ministrar aulas e divulgar a Capoeira Regional" que, de acordo com Izaltino Souza Couto, filho do Mestre Zoião e autor do prefácio da obra supracitada, "era totalmente desconhecida naquela cidade, pois o município de Vitória da Conquista faz divisa com Minas, e os costumes são mais mineiros” (COUTO, 1999 , p. 8-9) 9 .

Segundo o Mestre Acordeon, o Mestre Zoião era jornalista, o que facilitava fazer registros fotográficos do período histórico vivido por eles, e lamenta não ter registros da presença dos

3 Adyjolvã Anunciação Couto, nascido na cidade de Jequié-BA. É conhecido no mundo da Capoeira por ter sido aluno do Mestre Bimba, no início da década de 60, que seguiu a orientação de seu Mestre, transmitida a ele por meio de uma comunicação sobrenatural, após sua morte, quando se encontrava "em estado de sonolência", busca "integrar", ou "unificar as artes da capoeira Angola e Regional”. (COUTO, 1999, p. 10)

4 Centro Social Urbano-CSU.

5 José Fernandes Pedral Sampaio e Hélio Ribeiro foram diplomados, respectivamente, prefeito e vice-prefeito no dia 16 de dezembro de 1982. O vice-prefeito Hélio Ribeiro, ao assumir a prefeitura em toda ausência do titular, sempre apresentava muita autonomia. Durante os quatro meses de afastamento de Pedral da Prefeitura de Conquista, a chefia do executivo municipal foi entregue ao vice. Com a ida do prefeito José Pedral Sampaio para a Secretaria Municipal dos Transportes, assumiu definitivamente a prefeitura o vice-prefeito Hélio Ribeiro, a solenidade ocorreu no dia 12 de março de 1987, na Secretaria Municipal de Educação e Cultura (SOUZA, 2010).

6 Entrevista concedida por Antonio Santos Ferreira Filho, o mestre Acordeon, no dia 13 de julho de 2017.

7 Idem.

8 Idem.

9 Sobre este contraponto, é importante ressaltar que as memórias dos Mestres apresentadas até aqui apontam indícios de que alguns conhecimentos sobre a Capoeira Regional do Mestre Bimba estiveram presentes na cidade antes da vinda e estabelecimento do Mestre Zoião na cidade. 
outros Mestres na cidade, embora tivesse vivido na mesma cidade e não os tenha encontrado em épocas mais remotas. Assim, ele acredita que a presença dessa expressão cultural na cidade realmente se deu bem antes da presença do Mestre Manuel Sarará, corroborando os relatos da trajetória de vida do Mestre Donizete ${ }^{10}$, ao trazer incógnitas a respeito da presença de capoeiristas na fazenda Bem Querer, nos seus relatos do período da infância, ao observar o vaqueiro jogando capoeira.

Por outro lado, apesar de presenciarmos episódios diferentes em um mesmo momento, Portelli (1997) afirma que “[...] embora não possamos estabelecer uma norma geral de interpretação: apoiar-se em um episódio pode ser um caminho para salientar sua importância [...]” (PORTELLI, 1997, p. 29). Assim, esses aspectos são significativos se considerarmos que eles se mostram bastante presentes durante as narrativas e na própria identificação e caracterização desses Mestres, considerados como os principais disseminadores da prática da capoeira na cidade.

O Mestre Zoião foi recebido em Vitória da Conquista-BA, no início dos anos 1980, onde conseguiu adentrar em espaços e em locais como professor de Capoeira, aos quais, antes, nenhum outro capoeirista teve acesso, como o antigo colégio Edvaldo Flores, onde passou a ministrar as aulas de capoeira (COUTO, 1999). Segundo o Mestre Acordeon, isso facilitou tanto a entrada de vários alunos integrantes da classe média quanto a sua aproximação com vários outros representantes políticos, militares e outras instâncias sociais, como afirma Couto (1999):

\begin{abstract}
Além de outras grandes personalidades do Estado, a exemplo do general e ex-governador Juracy Magalhães, ex-governador Dr. Régis Pacheco, do deputado e ex-prefeito Dr. Raul Ferraz, prefeito Dr. Orlando Leite, ex-prefeito Dr. Fernando Spínola, Renato Vaz Rebouças, ex-prefeito membro da Academia de Letras de Vitória da Conquista, Dr. Nilton Gonçalves, Dr. Isaías Viana de Andrade, cirurgião dentista, especializado em ortodontia e um grande poeta. Hélio Ribeiro Santos, natural de Jequié-BA, ex-funcionário do Banco do Brasil, Cursulista, membro do Rotary Clube, presidente de várias agremiações de Vitória da Conquista-Ba. (...) (COUTO, 1999, p. 9).
\end{abstract}

Assim como aconteceu em Salvador, a presença da terminologia "Desportiva" na nomenclatura de grupos se apresenta em associações de capoeira em Vitória da Conquista, com incentivo do Mestre Zoião. Essa nomenclatura utilizada durante esse período em Vitória da Conquista contribuiria para que a sociedade tivesse o mesmo olhar que se tinha para o esporte, pois na ótica social o rótulo de prática esportiva distanciava os praticantes de capoeira das tensões relacionadas ao preconceito étnico-racial e das desigualdades sociais vigentes. Ademais, essa expressão cultural era associada ao lugar que pertencia no século XIX, no Código Penal brasileiro.

[...] Ele fazia questão que você tivesse praticando o esporte, mas ele queria conhecer quem eram os responsáveis por sua pessoa, pai, mãe, avó, para ter todo esse entendimento, e falar a importância da Capoeira e como a Capoeira era, porque ali naquele período já existia o

10 De acordo com os relatos de história oral de vida do Mestre Donizete, constata-se que a capoeira foi vista pela primeira vez na cidade de Vitória da Conquista-Bahia apenas a partir das décadas de 1950 e 1960. Suas práticas eram decorrentes da dinâmica ocorrida nos "quintais" até ocupar os espaços da "rua". Posteriormente, o final da década de 1960 foi marcado pela emergência desta prática corporal vista em um circo, como relatou o Mestre Sarará ao tratar da origem da capoeira nesta cidade. (SILVA; MARTA, 2019). 
preconceito, o racismo, as diferenças e as desigualdades nos esportes, e as famílias negavam muito. Até pra gente fazer Capoeira era difícil. Meu caso mesmo, meu pai não dava muita importância, e até hoje ele respeita, mas não teve presente constantemente. Meu avô já não gostava. Ele deixava bem claro, que ele não tinha simpatia. Ele alegava atitude mesmo, a violência, o racismo. Ele achava que a Capoeira era coisa de vagabundo, de Malandro, de marginais, porque também ele assistia muitas coisas $(. . .)^{11}$

De acordo com Vieira e Assunção (2009), era preciso amenizar conflitos sociais entre os anos de 1970 e 1980 quando se tratava da capoeira, já que a ideia era convencer a opinião pública de que essa prática corporal não era "coisa de marginal”. Segundo esses autores, a capoeira ia ao encontro de toda uma corrente nacionalista que tinha como objetivo fazer dela não somente um esporte, mas a "luta brasileira", expressão privilegiada da identidade nacional, como eles nos mostram:

\begin{abstract}
No início dos anos 1970, os capoeiristas ainda tinham algo de exótico. A própria Capoeira era vista como uma manifestação cultural que buscava se afirmar como esporte, cujo lugar "natural" seriam as comunidades mais pobres e periféricas, de população predominantemente afrodescendente. Em instituições mais elitizadas, a Capoeira ainda causava estranheza e, de fato, muitas delas fechavam suas portas para essa prática. Era necessário, portanto, um grande esforço de "organização", dando continuidade à trajetória iniciada pelos capoeiras da primeira metade do século XX. (VIEIRA; ASSUNÇÃO, 2009, p. 10).
\end{abstract}

O relato do Mestre Acordeon e o pensamento dos autores citados nos ajudaram a refletir sobre a forma como a capoeira era vista nesse período pelas famílias conquistenses, pois ela era negada e associada, ao mesmo tempo, às práticas criminais que colocavam os indivíduos num patamar social excludente. Segundo o Mestre Acordeon, uma das contribuições que fizeram com que a capoeira fosse vista de forma menos preconceituosa perante o racismo predominante na cidade foi a implementação de aulas em vários espaços na cidade, levando a capoeira a ter maior visibilidade social, como é possível perceber em seu relato:

[...] Neste período, (anos 80) aqui já estava Mestre Zoião, Hélio Ribeiro aqui do outro lado tinha um grupo de pessoas do "Projeto Recriança”, fazendo o fortalecimento da Capoeira dentro das comunidades, e quando Zoião entra no AABB, na "Sauna Center", no "Ginásio de Esportes", no "CSU”, no "Tiro de Guerra”, no "Batalhão de Polícia”, no "Colégio Centro Integrado", na "Escola Normal”, no "Edvaldo Flores”, e foi realizar um grande evento dentro do Centro de Cultura e outro dentro do "Clube Social" até chegar ao "Colégio Diocesano" e no "Colégio Padre Palmeiras", foi com o intuito de fortalecer a Capoeira dentro da sociedade de Vitória da Conquista, levando para a sociedade de altas condições financeiras, quanto aquelas que moravam nas periferias, nas comunidades mais simples, que todos tinham direito e tem direito ao acesso da arte da Capoeira, mesmo ele lidando com algo que já é cuidadoso e que realmente ele tem uma forma de entrar pra conseguir dizer: não ao preconceito e ao racismo ${ }^{12}$.

É possível compreender que a presença da capoeira em variados espaços na cidade também demandava discutir questões raciais na estrutura social. A luta antirracista tornou-se uma realidade na década de 1980 por meio da ocupação dos espaços na cidade para a prática da capoeira. De acordo com Almeida (2018), essa estrutura reproduz estratégias racistas no campo político, social e econômico, no intuito de discriminar pessoas ou grupos de forma

11 Entrevista concedida por Antonio Santos Ferreira Filho, O Mestre Acordeon, no dia 13 de julho de 2017.

12 Entrevista concedida por Antonio Santos Ferreira Filho, O Mestre Acordeon, no dia 13 de julho de 2017. 
sistemática. Dessa maneira, a luta antirracista ainda tem causado enfrentamento no processo de disseminação da Capoeira na cidade, devido ao não desaparecimento do preconceito e discriminação para com os capoeiristas, conforme as falas do Mestre Acordeon relacionadas ao racismo e ao preconceito social.

O Mestre Acordeon fala sobre ações prioritárias apresentadas pelos capoeiras da cidade na construção do Plano de Ação da Igualdade Racial e ressalta que as demandas históricas da capoeira foram retiradas do plano. Essas políticas, de acordo com o Mestre, vêm sendo discutidas na cidade há dez anos e, atualmente, através do Conselho de Mestres de Capoeira da cidade, que reúne, além dos Mestres considerados os mais antigos da cidade (Mestre Manoel Sarará, Mestre Bell, Mestre Zelito), outros que compõem o novo quadro atual de mestria na cidade. Sendo assim, a finalidade desse Conselho, segundo o Mestre Acordeon, é "discutir com a gestão pública, com a Coordenação de Igualdade Racial, com a Educação e com representantes na Câmara de Vereadores para que fortaleça as ações da Capoeira na cidade, para dar mais retorno e apoio"13.

Mesmo cercada por tensões e conflitos no âmbito da falta de apoio à capoeira pelos governantes da cidade, entre outros, o Mestre Acordeon observa toda sua trajetória e luta para ser reconhecido e respeitado a partir de sua significância social, levando a capoeira e o nome da "Associação de Capoeira Viva Conquista”. Há a preocupação do Mestre Acordeon em dar continuidade ao processo de ampliação da prática em diferentes localidades, de modo que os professores e Mestres possam transmitir seu legado pela cidade, ainda que constituam outras formações de grupos compostos por outros nomes.

Nesse ponto, levantamos a reflexão sobre a estrutura identitária do Mestre Acordeon, trazendo um exemplo do processo de construção de um enquadramento de memória. A definição desse conceito surge a partir de um diálogo de Michael Pollak (1989) que delimita o enquadramento de memória como a ação de determinados grupos em defender as fronteiras daquilo que o grupo tem em comum, definir seus pontos de referências e fortalecer o seu sentimento de pertencimento (POLLAK, 1989).

Percebemos que o processo de difusão das artes marciais na cidade, concomitantemente com o que aconteceu com a capoeira, fez com que, posteriormente, muitos capoeiristas as praticassem simultaneamente com outras lutas, ao passo que a Capoeira adquiriu outra notabilidade social, como diz o Mestre Acordeon:

\footnotetext{
[...] Hoje a gente vê o capoeirista fazendo Jiu-jitsu, fazendo judô, a gente vê o jiu-jitsu e o judô fazendo Capoeira, até chegar a nível de mundo, uma luta que tem a arte da Capoeira inclusa em seus grandes campeonatos, grandes torneios, grandes lutadores utilizando os conhecimentos e mecanismos da Capoeira. Usando a Capoeira como luta, como arte e como dança, como cultura. Então acho que a Capoeira fortaleceu vários eixos ${ }^{14}$.
}

Portanto, no final dos anos 1980 e início dos anos 1990, houve um crescimento acentuado em relação à participação das pessoas nas aulas de capoeira em Vitória da Conquista-BA, havendo "a inclusão da Capoeira na sociedade de Vitória da Conquista, e isso levou a um incentivo muito saudável, muito bacana, para os capoeiristas daquela época da prática”, como nos relata o Mestre Acordeon. Sobre esse assunto, Vieira e Assunção (2009) nos trazem pistas

13 Entrevista concedida por Antonio Santos Ferreira Filho, O Mestre Acordeon, no dia 13 de julho de 2017. 14 Idem. 
para ajudar a compreender aquilo que aconteceu em Vitória da Conquista-BA, ao tratar do mesmo fato na cidade de Salvador-BA. Os autores destacam que

\begin{abstract}
A geração de capoeiristas que se formou a partir dos anos 1980 está, de fato, participando de uma transição fundamental na história dessa arte. Se os atuais praticantes se acostumaram a ouvir de seus mestres e professores histórias sobre perseguição, rodas interrompidas pela polícia e correrias nas praças e festas de largo, a realidade que passaram a viver é, regra geral, completamente diferente. A Capoeira tem-se inserido nas instituições e no contexto político mais amplo por muitas vias, alterando dramaticamente sua prática e seu significado. Este cenário acelerado de mudança traz novos desafios tanto para os capoeiristas quanto para o Estado e os produtores culturais. (VIEIRA; ASSUNÇÃO, 2009, p. 10).
\end{abstract}

Esses desafios citados pelos autores estão fortemente presentes nos discursos dos Mestres entrevistados, pois, ao comparar a capoeira atual de Vitória da Conquista com momentos de outrora, o Mestre Acordeon reconhece que a capoeira está sendo mais valorizada. Entretanto, é perceptível, em seu discurso, a prevalência das tensões e conflitos que possivelmente perduraram desde o período do coronelismo em Vitória da Conquista-BA nos anos de 1950. De acordo o Mestre Acordeon:

[...] hoje aqui na cidade de Vitória da Conquista ou mesmo região, eles encontram hoje uma
Capoeira bem mais trabalhada, bem mais conscientizada, com mais respeito e mais valori-
zação. Encontramos uma Capoeira em Vitória da Conquista com resistência de aceitação,
com preconceito, vamos dizer assim, com perseguição de polícia e de outros seguimentos
também, que ali o capoeirista não tinha o direito de ir e vir. E hoje o praticante de Capoeira
em Vitória da Conquista tem o direito de se envolver com grandes encontros e batizados e
eventos de Capoeira $^{15}$.

Por fim, os relatos do Mestre Acordeon nos trouxeram possibilidades para perceber sua constante luta a favor dos direitos conquistados pelos capoeiristas na cidade, ao levarmos em consideração o processo de ocupação de seus espaços de apropriação, disseminação e prática. As memórias de sua trajetória de vida trouxeram marcas de lutas, tensões, disputas e conflitos estampados claramente em cada conquista feita por ele, eminentemente proporcionada através de sua escolha em ter dedicado sua vida em favor da permanência e continuidade da capoeira em Vitória da Conquista-BA.

\title{
O Mestre Pantera e os conflitos durantes as tentativas DE ESPORTIVIZAÇÃO
}

Os relatos do Mestre Pantera trazem memórias da difusão da capoeira em locais não tradicionais (academias de prática de diversas atividades físicas), além de revelar os conflitos e tensões ocorridos nesse processo. O Mestre coloca em discussão os caminhos e suas adversidades na preservação da tradição dos fundamentos dessa expressão cultural; revela em seus relatos a tradição de legado africano preservado através de sua educação familiar, apontando sua casa como um dos espaços de perpetuação da capoeira, nesse caso, através de seu irmão:

[...] Neste quintal. Isso aqui era tudo aberto (aponta para o quintal). Essa casa não existia. Meu irmão que me ensinou a Capoeira. Eu comecei a fazer a Capoeira aqui. Aqui tinha um pé de abacate, um pé de banana. A gente acordava 5 horas da manhã, meu irmão me acor-

15 Entrevista concedida por Antonio Santos Ferreira Filho, O Mestre Acordeon, no dia 13 de julho de 2017 
dava, eu e Nenzin e Derneval, que tá morando em São Paulo. Os outros não queriam. Zé Carlos - chamava "Padeiro" porque ele era padeiro. O Mestre dele se chamava Caranguejo. Comecei na Capoeira com 8 anos de idade. Comecei a aprender Capoeira neste quintal ${ }^{16}$.

As memórias do Mestre Pantera sobre sua infância nos trazem as consequências de uma estrutura sociocultural construída e modificada ao longo dos processos históricos (CORSARO, 2011). Entretanto, mesmo com o desenvolvimento econômico do município, sua família ainda estava inserida numa realidade que vivenciava o processo de exclusão social na cidade. Sendo assim, desde cedo, o Mestre Pantera adquire conhecimentos necessários para participar do mundo adulto, tendo a realidade da pobreza e a necessidade de trabalhar para dar continuidade aos treinamentos de capoeira. Atualmente, ele reside no Bairro Guarani, e "atravessava a cidade de ponto a ponto para ir até a academia de Manoel Sarará, no Bairro Alegria”. Sem transporte público, o trajeto era feito a pé.

A desvalorização da capoeira e da figura do Mestre foi um dos assuntos tratados durante os relatos do Mestre Pantera, pois ele demonstrou que é impossível viver sem valorização financeira, dificuldades que se mostraram latentes nos relatos dos entrevistados. As possíveis causas dessa desvalorização estão apontadas para a sua origem: o processo de escravidão que os povos negros vivenciaram no Brasil e toda a ideologia forjada para justificar esse sistema; a criminalização dessa manifestação cultural desde 1890 até os anos de 1930/40; as verdades construídas em torno de sua descriminalização, sustentadas pelo discurso de símbolo de identidade brasileira, no período do Estado Novo.

O processo de criminalização da capoeira, de acordo com Silva e Marta (2016), concretizou a proibição da prática nas ruas e monitorava e perseguia os capoeiristas por meio de dispositivos disciplinares para criminalizar e punir. Dessa maneira, em 1890, logo após a abolição da escravatura, a capoeira foi considerada uma prática criminosa, enquadrada no Código Penal (CP) e demais Leis, Posturas e Decretos. O Art. 402 do CP de 1890, que trata "Dos Vadios e capoeiristas", proibia:

Art. 402. Fazer nas ruas e praças públicas exercícios de agilidade e destreza corporal conhecida pela denominação capoeiragem: andar em carreiras, com armas ou instrumentos capazes de produzir lesão corporal, provocando tumulto ou desordens, ameaçando pessoas certas ou incertas, ou incutindo temor de algum mal; Pena - de prisão celular de 2 a 6 meses. (REGO, 1968, p. 292).

Paralelo a isso, os estudos de Silva e Marta (2017) discutiram sobre as "verdades" no século XIX, pautados nas obras de Michael Foucault, que mantiveram a capoeira como uma prática criminalizada, sendo considerada uma doença moral proliferada na cidade. A estrutura social, vista a partir da lógica higienista europeia, propagava as práticas de ginástica como profilaxia para regenerar a "raça", nesse caso, os negros. Assim, tendo em vista que a sociedade buscava disciplinar esses corpos, esses autores consideram que o século XX abarca conflitos promovidos pelo ideal de civilização do comportamento social dos capoeiristas e, concomitantemente, a padronização de suas práticas corporais, ao ponto de esportivizá-las.

Costa (2013) explica que os exercícios físicos, no século XX, tiveram grandes influências da ginástica europeia, entre elas, a francesa, a alemã e a sueca. Emergem daí discursos que contribuíram para que Getúlio Vargas, durante o Estado Novo, institucionalizasse a capoeira

16 Entrevista concedida por Gomar Santos Novais, o Mestre Pantera, no dia 19 de julho de 2017. 
como "ginástica genuinamente brasileira", sendo "um movimento que se valia da valorização e nacionalização da cultura” (COSTA, 2013, p. 46).

Essa desvalorização é explicada na obra dedicada à Capoeira Regional, de Hélio Campos (2009), ao dizer que

[...] os estudiosos, em sua maioria, são unânimes em atestar que a capoeira sofreu uma forte resistência durante toda a sua trajetória, advinda do processo brasileiro de escravidão e, sustentada pelo racismo e pelo preconceito, é entendida como uma atividade de negros, malandros, vadios, marginais e desocupados. (CAMPOS, 2013. p. 108).

Essa desvalorização tem levado os capoeiristas para outros países, em busca de melhores condições de vida, onde a essa manifestação cultural está ganhando novos adeptos e sendo difundida rapidamente em nível mundial. Essa valorização também tem garantido a sustentabilidade desses capoeiristas. Segundo Falcão (2005), nos últimos anos "consta-se a saída de um expressivo número de brasileiros para o exterior em busca de melhores condições de sobrevivência contribuindo, efetivamente, com o processo de expansão da Capoeira no mundo" (FALCÃO, 2005. p. 112). O processo de disseminação se configurou com a abertura de novos espaços, que fizeram com que a capoeira se inserisse em academias de ginástica, junto com diversas práticas corporais, como nos conta o Mestre Pantera:

\footnotetext{
[...] da Sauna Center eu passei dá aulas lá na Atlética Máster. Eu conheci Sérgio Magalhães que é o Diretor da FTC ${ }^{17}$. Se você conversar com ele... Pantera trabalhou contigo? Conheci Sérgio Magalhães na Sauna Center era um professor de Educação Física, tava começando a carreira. Ele era professor de Educação Física, fez o mestrado, doutorado dele. Ele mais três colegas abriram uma academia - a Atlética Máster e me convidou pra ser professor de Capoeira... Não tinha outro professor de Capoeira lá ${ }^{18}$.
}

São nesses espaços que a capoeira se depara com os desafios e enfrentamentos das tensões e conflitos colocados em questão, já que, de acordo com o Mestre Pantera, a discussão dos valores tradicionais da roda "entrou em conflito com a presença e influência da mídia", especialmente, da programação televisiva de alcance nacional, revistas e no cinema, gerando, assim, uma maior visibilidade dessa expressão cultural.

Assim como aconteceu com outras práticas corporais, como as artes marciais orientais, a capoeira passou por um processo de massificação por influência do processo de mercadorização das práticas corporais, dos meios de comunicação de massa (cinema, televisão e revistas) e do processo de esportivização. Essa massificação das práticas corporais, como aconteceu com as artes marciais e outros tipos de atividade física, ginástica e esporte foi influenciada, segundo Marta (2004), pela divulgação em "matérias jornalísticas sobre os benefícios da atividade física, nas novelas difusoras de padrões de beleza estética, no jornalismo esportivo e nos filmes de ação patrocinados pela indústria de cinema norte-americana” (MARTA, 2004, p. 5).

Entretanto, o Mestre Pantera traz consigo tensões e conflitos gerados em torno dos fundamentos da tradição da capoeira a respeito das graduações mencionadas, já que não havia uma preocupação em "ganhar dinheiro", e sim em seguir as etapas coniventes aos períodos preparatórios para culminância de seu evento realizado anualmente. Devido a isso, ele lembra que havia grupos de capoeira que aumentaram a frequência na realização desses eventos,

17 Faculdade de Tecnologia e Ciências - FTC.

18 Entrevista concedida por Gomar Santos Novais, o Mestre Pantera, no dia 19 de julho de 2017. 
permitindo, assim, a diminuição do tempo de cumprimento desses estágios de formação.

Por um lado, isso possibilitou, de acordo com os Mestres entrevistados, que os alunos se aproximassem da capoeira e dos benefícios que ela proporciona mediante sua prática. Por outro lado, esse novo sistema de graduação alimentou a conjuntura do mercado, transformando-se em um símbolo que garantiu a ostentação do poder, sendo que "para passar de uma graduação para outra, o aluno deve pagar" certa quantia estabelecida pelo Mestre, como aparece nas análises dos estudos de Silva (2003):

[...] tudo isto é fruto de um modelo político que se apoia na hierarquia padronizada por diplomas e, na capoeira, por cordões ou cordéis, ou seja, parece que, em grande número, os capoeiristas treinam em prol de cordões mais elevados que lhes garantam um respeito que às vezes não foi conquistado, mas comprado, como se o cordão fosse tudo na capoeira. (SILVA, 2003, p. 132).

Esse discurso é reforçado ainda mais quando Vieira (1998) relata as críticas de alguns Mestres de Capoeira, os quais afirmam que os mestres que se apropriam dessas práticas "estão se vendendo”. Sobre esse fato, ele ainda diz:

Atualmente, a exemplo do que se faz nas lutas orientais, o capoeirista é submetido a um exame a cada mudança de corda e, para isso, paga uma taxa fixada por cada academia. Em alguns casos, os exames - geralmente de periodicidade semestral - acabam se transformando em significativa fonte de renda para os mestres de capoeira. (VIEIRA, 1998, p. 115).

A partir do que Vieira (1998) traz nesse fragmento, podemos perceber que cresce cada vez mais o número de grupos de capoeira que "graduam" os alunos em um curto intervalo de tempo. Desse modo, a causa que leva ao aumento desses grupos pode estar relacionada à representação de seu grupo em outros espaços que tenham esses eventos festivos de capoeira, assim como acontece nos eventos esportivos. Consequentemente, há um aumento, tanto da quantidade de alunos formados, quanto da de representantes de grupos de capoeira nas "competições" durante a realização desses eventos, através de exibições de golpes, acrobacias e etc. Dessa maneira, ao estarem mergulhados nessa lógica de mercadorização, é possível que esses mestres não tenham acompanhado os elementos que compõem o universo do processo de aprendizado, trazido a partir da temporalidade contida nos princípios do reconhecimento da mestria, como nos mostra Abib (2004):

[...] diz uma cantiga de capoeira que 'só o tempo te faz mestre', e isso implica que o mestre de capoeira seja alguém que possua, além da capacidade e habilidade na prática do jogo, muita experiência de vida. O reconhecimento como mestre, se dá então naturalmente, por parte da comunidade da qual ele faz parte (...). O título de mestre só tem legitimidade, quando atribuído pelo grupo social ao qual representa, que, em última instancia, é quem delega autoridade às suas lideranças. (ABIB, 2004, p. 135. Grifos do autor).

A capoeira, vista por essa ótica de mercadoria vai se perdendo no mundo da técnica, ao analisarmos que, nos dias de hoje, a formação de um Mestre de Capoeira se resume em apenas cumprir etapas durante uma suposta formação para alcançar o "mestrado", mesmo possuindo pouca idade. Sobre isso, Vieira (1998) reforça:

atualmente, na maioria das escolas, o grau de mestre identifica simplesmente um nível de hierarquia dos cordéis de capoeira. As federações e a confederação de capoeira estabelecem critérios objetivos para a obtenção do título. Em algumas academias o capoeirista pode che- 
gar a mestre em dois ou três anos, mesmo sem ter a experiência de ensinar a luta. (VIEIRA, 1998. p. 114).

Essa "antecipação" do tempo de aprendizagem, através da "formação" precoce do "capoeira”, resulta na negação das matrizes que geraram a capoeira e, ao mesmo tempo, na reafirmação do uso de métodos de ensino em que os "jovens" mestres ou professores acabam extrapolando ou cometendo atrocidades nas aulas de capoeira.

Para tanto, buscamos nas análises da dissertação de Marta (2004) as implicações do capitalismo na disseminação e difusão das artes marciais, em São Paulo, através da utilização dos argumentos da estética e da saúde. Segundo esse autor, esse processo de disseminação construiu um ideal de corpo e estética que se consolidou na "indústria do fitness", transformando as artes marciais em produto de mercado, algo semelhante ao que aconteceu com a capoeira. Sendo assim, torna-se mais um produto a ser ofertado pelas academias aos clientes que, motivados pela estética do corpo, como explica Alves e Montagner (2008), buscaram na capoeira não a sua complexidade de gestos, ritos, história e musicalidade, mas sim um corpo trabalhado e bonito, propiciado pela exigência do treinamento (ALVES; MONTAGNER, 2008).

O processo de transformação da capoeira em mercado também foi estudado por Araújo (2008), resultando em sua dissertação intitulada "A capoeira na sociedade do capital: a docência como mercadoria-chave na transformação da capoeira no século XX”. De acordo com esse pesquisador, com o afastamento da capoeira dos locais abertos e públicos (praças, ruas) e das periferias, situando-se em ambientes fechados, se dá o início da relação de troca, motivada também pelas necessidades econômicas. Isso, por sua vez, está relacionado à discussão de Araújo (2008) sobre a visão social que se tinha sobre o praticante de capoeira, que antes era tido como "malandro" e passa a ser considerado "desportista". Nessas circunstâncias, a capoeira se insere "na imensa coleção de mercadorias da sociedade capitalista e, como tal, passa a ter de se submeter aos interesses daqueles que viriam a consumi-la" (ARAÚJO, 2008, p. 36).

Percebe-se, conforme explica Batistta (2014), a utilização das construções civilizatórias negras para a produção de imagens exóticas, carregadas de estereótipos para estruturar formas de atrativos turísticos do Estado, transformando os saberes dos povos negros em produtos a serem consumidos. Nesse sentido, a cultura local, centro das atenções, se torna um objeto altamente comercializável e explorável no mercado do turismo, tornando-se parte integrante da imagem pública da Bahia (BATISTTA, 2014).

A tentativa de construir um trabalho de capoeira nas academias teve um período curto. Nesse período, o Mestre Pantera nos diz que ganhou dinheiro que lhe possibilitou a compra de uma casa, sendo uma remuneração mensal que recebia pelos seus serviços prestados nos espaços citados em seus relatos, o que deixou de acontecer nos anos seguintes. A remuneração fixa e periódica não acontece em espaços próprios.

Assim, o Mestre Acordeon vive de forma semelhante às condições financeiras do Mestre Pantera. Essa situação nos leva a comparar aquelas vividas por vários outros Mestres de Capoeira consagrados, como nos lembra Silva (2017), ao dizer que "apesar do fortalecimento político-econômico da Capoeira, que os mestres das primeiras academias empreenderam, nos deparamos com o fato de grandes nomes dessa prática terem morrido em situação financeira 
precária” (SILVA, 2017. p. 68). Ainda conforme análises realizadas por Silva (2017), essa situação reflete a face mais perversa da relação entre o capitalismo e a classe trabalhadora. E mesmo a eminente "ascensão social e cultural da Capoeira baiana não favoreceu a conquista de direitos sociais básicos a inúmeros mestres” (SILVA, 2017, p. 69).

Depois de passar por diversas localidades durante seu processo de disseminação, além de enfrentar vários conflitos, seja pelo fato de ter dado aulas em troca de acesso a uma sala de aula para que pudesse "treinar" sua turma de capoeira em turnos opostos, falta de apoio financeiro, custeio mensal de aluguel e outras despesas fixas, o Mestre Pantera, hoje, tem ajuda e motivação dos seus alunos.

Portanto, à medida que essa prática foi se espalhando pela cidade, foi notável a necessidade de se formarem novos capoeiristas capacitados para assumirem os locais de práticas para o ensinamento de novos praticantes. Ou seja, no intuito de fazer "germinar" outros núcleos de práticas compostos por professores e contramestres advindos da mesma fonte de conhecimento, que, nesse caso, está referida na sede do Movimento Cultural Consciência Negra.

Por fim, temos a capoeira enquanto uma memória refletida através do marco guardado pelo Mestre Pantera. Os relatos orais apresentados por ele sobre as suas experiências adquiridas durante a sua trajetória de vida revelaram valores, interações sociais, escolhas profissionais, enfrentamentos relacionados aos conflitos e tensões trazidos a partir de suas dificuldades encontradas ao disseminar a capoeira em variados locais da cidade. Isso porque as memórias constituídas a partir de suas lutas continuam eminentes no grupo, conforme afirma Halbwachs (2006), já que seus relatos possibilitaram conceber as permanências nos traços de lembranças, logo se constituem como importantes mecanismos da memória. A memória do grupo, para ele, deve ser preservada, assim como afirma Halbwachs (2006), ao se tratar do espaço como gerador de uma memória coletiva que deve ser preservada, capaz de identificar um grupo social importante nesse processo de construção da própria identidade.

Essas possibilidades de práticas apontadas pelo Mestre Pantera se iniciam ainda em meio ao "quintal" de sua casa, estendendo-se até o "quintal" da casa do Mestre Sarará. Elas continuaram ferreamente desde a luta e resistência até chegar a outros "quintais" não habitados por capoeiristas da cidade. Assim, a capoeira "germinada" no "fundo do quintal" ganhou sua força e provocou o próprio sistema ao vê-la a partir de outro prisma, diferentemente da realidade que se apresentava na cidade de outrora.

Todavia, apesar desses novos "quintais" terem sido substituídos pelas academias e outros locais de práticas corporais, não podemos desconsiderar as dificuldades que levaram os Mestres de Capoeira a submeterem seus trabalhos aos donos desses recintos, pois a dedicação à capoeira fez com que o Mestre Pantera abdicasse de outras formas de trabalhos formais. Assim, ao buscar outra forma de ressignificar a memória da capoeira na cidade, ele marca sua presença e contribuição através dos eventos de nível nacional, os quais sempre proporcionaram a presença de grandes capoeiristas e Mestres de Capoeira renomados em todo o país desde o início dos anos de 1990.

A memória da capoeira em Vitória da Conquista-BA foi se modificando, mesmo com a permanência de disputas e conflitos de ordem identitária, hierárquica e também econômica. Portanto, foi possível identificar, a partir dos relatos do Mestre Pantera, o quanto a sua 
contribuição durante o processo de difusão da Capoeira na cidade foi importante, a fim de resistir e manter viva sua prática.

\section{CONSIDERAÇõES FINAIS}

Os estudos sobre a capoeira em Vitória da Conquista trouxeram a grande roda da cidade e os conflitos provocados pelas tensões e disputas durante o processo de disseminação. A partir disso, foi possível compreender: (i) a relação entre as memórias apresentadas pelos Mestres de Capoeira e as adversidades que os tencionaram através de disputas de cunho socioeconômico e étnico-racial; (ii) a superação advinda de suas trajetórias de vida desde a infância; as vivências conflituosas na escola excludente; (iii) a vida rural; a busca de empregabilidade e sustentabilidade; (iv) a desmoralização; (v) a resistência ao preconceito racial; (vi) os enfrentamentos políticos; (vii) as disputas de memórias; (viii) a ocupação de espaço e autonomia; (ix) as iniciativas que impulsionaram a disseminação da capoeira.

Por outro lado, as memórias reunidas em torno dos lugares frequentados por eles nos levaram a compreendê-los como protagonistas de um processo de lutas e resistências, que pouco foi valorizado pelo poder público e incompreendido pela sociedade da época. Esse fato impossibilitou que a capoeira tomasse maiores proporções em lugares em que deveria estar atualmente. Reconhecemos que essa prática se manteve em um jogo de "altos e baixos", resistindo continuamente às próprias intencionalidades do mercado, da mídia e das indústrias de esporte.

Essas formas de disputas marcaram, também, a memória dessa arte na cidade através de alguns signos de legitimação da cultura negra nesse espaço, uma ação de legitimação da prática de si perante outras práticas dentro da cidade. Todos, em conjunto, são elementos que, a partir das entrevistas feitas com os Mestres, trouxeram indícios que ajudaram a pensar a memória múltipla da capoeira em Vitória da Conquista-BA durante a segunda metade do século XX, período de maior atuação desses indivíduos.

Foi perceptível nesta experiência o fato de a relação entre memória e história ser materializada durante as narrações. Isso só é possível se a entrevista se torna resultante do trabalho comum de uma pluralidade de autores em diálogo, o que faz emergir as vozes de narradores que vão se cruzando, alternando falas e lembranças, confirmando o mesmo testemunho a partir de pontos de vista diversos (PORTELLI, 2010, p. 10).

Portanto, este estudo contribuiu para outras pesquisas relacionadas ao processo de investigação sobre como as práticas corporais se espalharam por vários lugares do país e como isso impacta na sociedade atual, sobretudo na construção de memórias individuais e coletivas das populações negras. O preconceito histórico contra a prática da capoeira e a trajetória de luta dos Mestres para manterem-na viva até os dias de hoje são mazelas a serem superadas na luta antirracista.

A metodologia da História Oral foi renovadora nesta pesquisa visto que poucas pesquisas em história do esporte se aprofundam neste campo científico, dada a preferência pelos periódicos sistematizados a partir de outros métodos. As entrevistas com os Mestres coadunam-se com as temáticas recentes em torno dos conflitos recorrentes do processo exposto ao decorrer do trabalho. Conflitos esses que, mesmo silenciados historicamente, 
ainda são, majoritariamente, protagonistas e sujeitos ativos no que se refere à memória esportiva enquanto legado científico e social perante futuras vozes que emergirão a partir dessas já existentes. 


\section{REFERÊNCIAS BIBLIOGRÁFICAS}

ABIB, Pedro Rodolpho Jungers. Capoeira Angola: cultura popular e o jogo dos saberes na roda. 2004. 173. f. Tese (Doutorado em Educação) - Faculdade de Educação, Universidade Estadual de Campinas, Campinas-SP, 2004. Disponível em: https://grupomel.ufba.br/sites/grupomel.ufba. br/files/capoeira_angola_cultura_popular_e_jogos_dos_saberes_na_roda.pdf. Acesso em: 20 dez. 2017.

ALMEIDA, Silvio Luiz de. O que é racismo estrutural? Belo Horizonte-MG: Letramento, 2018.

ALVES, Leonardo Prata; MONTAGNER, Paulo César. A esportivização da capoeira: reflexões teóricas introdutórias. Conexões, Campinas-SP, v. 6, p. 510-521, 2008. Disponível em: https:// periodicos.sbu.unicamp.br/ojs/index.php/conexoes/article/view/8637853\#: :text=Este\%20 estudo\%20\%C3\%A9\%20resultado\%20de,e\%20favor\%C3\%A1veis\%20a\%20este\%20 fen\%C3\%B4meno. Acesso em: 19 de nov. 2017.

ARAÚJO, Benedito Carlos Libório Caires. A capoeira na sociedade do capital: a docência como mercadoria-chave na transformação da capoeira no século XX. 2008. 99 f. Dissertação (Mestrado em Educação) - Universidade Federal de Santa Catarina, Centro de Ciências da Educação, Programa de Pós-Graduação em Educação, 2008. Disponível em: https://repositorio. ufsc.br/xmlui/bitstream/handle/123456789/91592/258701.pdf?sequence=1\&isAllowed =y. Acesso em: 4 dez. 2019.

ARÓSTEGUI, Julio. A pesquisa histórica: teoria e método. Bauru: Edusc, 2006.

BATISTTA, Iury Abreu Tavares. Uso da imagem do negro para a promoção do turismo da Bahia. In: III Seminário Políticas para diversidade cultural, 2014. Disponível: https:// politicasparadiversidadecultural.files.wordpress.com/2014/07/spdc14_iury-abreu-tavares-batistta. pdf. Acesso em: 4 dez. 2019.

CALDAS, Alberto Lins. Oralidade, texto e história: para ler a história oral. São Paulo: Loyola, 1999.

CAMPOS, Lima. A capoeira. Revista Kosmos, Rio Janeiro, ano 3, n. 62, mar. 2013. Disponível em: https://itanobe.com/2013/08/17/revista-kosmos-1906/. Acesso em: 10 dez. 2009.

CID, Gabriel da Silva Vidal. O registro da capoeira como patrimônio cultural: usos da cultura como alargamento da cidadania nas políticas culturais. In: II Seminário Nacional História e Patrimônio Cultural - GT História e Patrimônio Cultural - ANPUH Brasil Núcleo de Documentação, História e Memória Rio de Janeiro. Rio de Janeiro. Anais [...]. UFRJ, 2018. Disponível em: https://anpuh.org.br/images/ANPUH/Anais\%20GT/GT\%20Hist\%C3\%B3ria\%20 e\%20Patrim\%C3\%B4nio\%20Cultural/Capa_Anais_II_Seminario_GT_ANPUH_Patrimonio_fiinal_ FINAL_COMPLETO.pdf. Acesso em: 17 fev. 2021.

CORSARO, William. Arnold. Sociologia da Infância. Porto Alegre: Artmed, 2011.

COSTA, Neuber Leite. Capoeira, Política Cultural e Educação. Tese (Doutorado em Educação) - Universidade Federal da Bahia, Faculdade de Educação, 2013. Disponível em: https://repositorio. ufba.br/ri/handle/ri/18186. Acesso em: 20 fev. 2018.

COUTO, Adyjolvã Anunciação (MESTRE ZOIÃO). Arte da Capoeira - História e Filosofia. Salvador: Gráfica Santa Helena, 1999.

ELIAS, Norbert; DUNNING, Eric. Deporte y Ócio en el Proceso de la Civilizacion. México: Fondo de Cultura Económica, 1995. 
FALCÃO, José Luis Cirqueira. Fluxos e refluxos da capoeira: Brasil e Portugal gingando na roda. Análise Social, Santa Catarina-PR, v. XL, n. 174, p. 111-133, 2005. Disponível: http:// analisesocial.ics.ul.pt/documentos/1218709063N7nVD0cp8Qb02OZ6.pdf. Acesso em: 2 dez. 2019.

FERRAZ, Ana Emília de Quadros. O urbano em construção: Vitória da Conquista, um retrato de duas décadas. Vitória da Conquista: UESB, 2001.

HALBWACHS, Maurice. A memória coletiva. São Paulo: Centuro, 2006.

MARTA, Felipe Eduardo Ferreira. O caminho dos pés e das mãos: Taekwondo. Arte marcial, esporte e colônia coreana em São Paulo (1970 - 2000). 2004. Dissertação (Mestrado em História) Pontifícia Universidade Católica de São Paulo, São Paulo, 2004.

MEIHY, J. C. S. B. Manual de história oral. São Paulo: Loyola, 2002.

MEIHY, José Carlos Sebe; HOLANDA, Fabíola. História oral: como fazer, como pensar. 2. ed. São Paulo: Contexto, 2010.

OLIVEIRA, David Eduardo de. Cosmovisão africana no Brasil: elementos para uma filosofia afrodescendente. Curitiba: Editora Gráfica Popular, 2006.

POLLAK, Michael. Memória, esquecimento, silêncio. Estudos Históricos, Rio de Janeiro, v. 2, n. 3, p. 3-15, 1989. Disponível em: http://www.uel.br/cch/cdph/arqtxt/Memoria_esquecimento_ silencio.pdf. Acesso em: 05 jul. 2017.

PORTELLI, Alessandro. A filosofia e os fatos: narração interpretação e significado nas memórias e nas fontes orais. Tempo, Rio de Janeiro, v. 1, n. 2, p. 59-72, 1997.

PORTELLI, Alessandro. Ensaios de história oral. São Paulo: Letra e Voz, 2010.

REGO, Waldeloir. Capoeira angola: ensaio sócio-etnográfico. Salvador: Editora Itapuñ, Coleção Baiana, 1968.

REIS, Leticia Vidor de Sousa. A capoeira: de doença moral à gymnástica nacional. Revista História, São Paulo, n. 129-131, p. 221-235, ago-dez. 1994. Disponível em: https://www. revistas.usp.br/revhistoria/article/view/18730\#: :text=Nesse\%20artigo\%20a\%20autora\%2C\%20 a,s\%C3\%ADmbolo\%20\%C3\%A9tnico\%20em\%20s\%C3\%ADmbolo\%20nacional. Acesso em: 9 out. 2017.

RUFINO, Patrícia Gomes. Circularidade: Discutindo inclusão nas perspectivas da educação das relações étnico-raciais (erer) afro-brasileiras, 2013. Disponível em: http://www. acordacultura.org.br/artigos/15102013/circularidade-discutindo-inclusao-nas-perspectivas-daeducacao-das-relacoes-etnicos-raciais-erer-afro-brasileiras. Acesso em: 7 maio 2020.

SILVA, Jonatan dos Santos, MARTA, Felipe Eduardo Ferreira. Capoeira e suas "verdades" não enunciadas: criminalizar para civilizar ou descriminalizar para esportivizar? In: XXIX Simpósio Nacional de História - contra os preconceitos: história e democracia. Anais [...]. Brasília/ UNB, 2017. Disponível em: https://www.snh2017.anpuh.org/resources/anais/54/1502841972_ ARQUIVO_Artigofinallanpuh2017.pdf. Acesso em: 17 fev. 2021.

SILVA, Jonatan dos Santos; MARTA, Felipe Eduardo Ferreira. "Do Quintal à Rua”: A Capoeira em Vitória da Conquista-BA na Memória do Mestre Donizete (1950/60). 2019. Disponível em: https://www.revistas.uneb.br/index.php/cenaseducacionais/article/view/8065/5228. Acesso em 22 dez. 2020.

SILVA, Jonatan dos Santos; MARTA, Felipe Eduardo Ferreira. “Dos Vadios e Capoeiristas” À 
Emergência do "Esporte Genuinamente Brasileiro”. In: VIII Encontro Estadual de História da ANPUH-BA. Anais [...]. Feira de Santana, 2016. Universidade Estadual de Feira de Santana. Disponível em: http://www.encontro2016.bahia.anpuh.org/resources/anais/49/1477694131_ ARQUIVO_artigodejonatan.pdf . Acesso em: 17 fev. 2021.

SILVA, José Milton Ferreira da. A Linguagem do Corpo na Capoeira. Rio de Janeiro: Sprint, 2003.

SILVA, Sammia Castro. Campo de saberes da capoeira cearense: um estudo sobre o Centro Cultural Capoeira Água de Beber (2002-2016). 2017. 170 f. Tese (Doutorado em Educação) Universidade Federal do Ceará, Faculdade de Educação, Programa de Pós-Graduação em Educação, Fortaleza, 2017. Disponível em: http://www.repositorio.ufc.br/bitstream/riufc/21800/1/2016_ scsilva.pdf. Acesso em: 20 mar. 2018

SODRÉ, Muniz. A verdade seduzida. Rio de Janeiro: Francisco Alves, 1983.

SOUZA, Belarmino de Jesus. Uma polis sertaneja, fora do eixo e fora do centro: imprensa e memória nas disputas políticas em Vitória da Conquista (1962-1992). 2010. 288 f. Tese (Doutorado em História Social) - Universidade Federal da Bahia, Salvador, 2010.

TAVARES, Julio Cesar de. Dança de guerra, arquivo e arma: elementos para uma teoria da capoeiragem e da comunicação corporal afro-brasileira. Belo Horizonte: Nandyala, 2012.

VIEIRA, Luiz Renato; ASSUNÇÃO, Matthias Röhrig. Os desafios contemporâneos da capoeira. Brasília: Ministério das Relações Exteriores, 2009. (Textos do Brasil, 14: Capoeira)

VIEIRA, Luiz Renato. O Jogo da Capoeira. 2. ed. Rio de Janeiro: Srint, 1998. 